\title{
Flavonoid Glycosides in Brassica Species Respond to UV-B Depending on Exposure Time and Adaptation Time
}

\author{
Susanne Neugart ${ }^{1, *}$ and Christiane Bumke-Vogt ${ }^{2}$ \\ 1 Division Quality and Sensory of Plant Products, Georg-August-Universität Göttingen, Carl-Sprengel-Weg 1, \\ 37075 Goettingen, Germany \\ 2 Leibniz-Institute of Vegetable and Ornamental Crops, Theodor-Echtermeyer-Weg 1, \\ 14979 Grossbeeren, Germany; bumke@igzev.de \\ * Correspondence: susanne.neugart@uni-goettingen.de; Tel.: +49-0551-39-27958
}

check for updates

Citation: Neugart, S.; Bumke-Vogt, C. Flavonoid Glycosides in Brassica Species Respond to UV-B Depending on Exposure Time and Adaptation Time. Molecules 2021, 26, 494 https://doi.org/10.3390/molecules 26020494

Academic Editors: Tuba Esatbeyoglu and Banu Bayram

Received: 2 December 2020

Accepted: 13 January 2021

Published: 18 January 202

Publisher's Note: MDPI stays neutral with regard to jurisdictional claims in published maps and institutional affiliations.

Copyright: (c) 2021 by the authors. Licensee MDPI, Basel, Switzerland. This article is an open access article distributed under the terms and conditions of the Creative Commons Attribution (CC BY) license (https:// creativecommons.org/licenses/by/ $4.0 /)$.

\begin{abstract}
Recently, there have been efforts to use ultraviolet-B radiation (UV-B) as a biotechnological tool in greenhouses. Leafy Brassica species are mainly considered for their ability to synthesize glucosinolates and are valued as baby salads. They also have a remarkable concentration of chemically diverse flavonoid glycosides. In this study, the effect of short-term UV-B radiation at the end of the production cycle was investigated without affecting plant growth. The aim was to verify which exposure and adaptation time was suitable and needs to be further investigated to use UV as a biotechnological tool in greenhouse production of Brassica species. It is possible to modify the flavonoid glycoside profile of leafy Brassica species by increasing compounds that appear to have potentially high antioxidant activity. Exemplarily, the present experiment shows that kaempferol glycosides may be preferred over quercetin glycosides in response to UV-B in Brassica rapa ssp. chinensis, for example, whereas other species appear to prefer quercetin glycosides over kaempferol glycosides, such as Brassica oleracea var. sabellica or Brassica carinata. However, the response to shortterm UV-B treatment is species-specific and conclusions on exposure and adaptation time cannot be unified but must be drawn separately for each species.
\end{abstract}

Keywords: quercetin glycosides; kaempferol glycosides; ultraviolet radiation; kaempferol-3-caffeoylsophoroside-7-glucoside; sinapic acid

\section{Introduction}

While one challenge in today's agriculture and horticulture is to ensure food security for the world's growing population, on the other hand, health-promoting foods for an aging population are in high demand [1]. Brassica species are known for their content of glucosinolates. However, the remarkable amounts of flavonoids, a well-known group of antioxidants, are rarely considered in Brassica species. Flavonoids are ubiquitous in plants [2]. The most important flavonoids in the human diet are quercetin and kaempferol, which are present as complex glycosides in Brassica species [3-5]. Flavonoids act as antioxidants [6] and shielding components [7] in plants and are of special interest due to their antioxidant activity, as well as anti-inflammatory and anti-cancerogenic effects in humans [8-10].

Brassica plants are close relatives and include six species described by the U-triangle, three of which are diploid (Brassica rapa $\mathrm{n}=10$ (AA), Brassica nigra $\mathrm{n}=8$ (BB), and Brassica oleracea $\mathrm{n}=9(\mathrm{CC})$ ), while the other three are allotetraploid hybrids (Brassica juncea $\mathrm{n}=18$ (AABB), Brassica napus $\mathrm{n}=19$ (AACC), Brassica carinata $\mathrm{n}=17(\mathrm{BBCC})$ ) derived from each pair of the three diploid species. Brassica species that share the same genome are thought to respond similarly to UV-B. The major flavonoids in various Brassica species are the complexes kaempferol 3-O-sophoroside-7-O-glucoside and quercetin 3-O-sophoroside7-O-glucoside and their hydroxycinnamic acid acylated forms [4,11,12]. Currently, the consumption of raw leafy Brassica species as baby leaf salads gained worldwide attention and provides an opportunity to increase flavonoids in the human diet. 
Ultraviolet radiation (UV; $290-400 \mathrm{~nm}$ ) comprises a relatively minor fraction of the total solar radiation reaching the earth's surface and is known to play an important role in regulating the growth, photosynthesis, and secondary plant metabolites of higher plants $[13,14]$. Most plants grown in greenhouses and plastic tunnels lack adaptation to UV radiation during their growth. Consequently, they have lower concentrations of flavonoids [15]. In modern agriculture, UV radiation has been considered harmful to plants because it reduces plant photosynthesis and thus plant growth. In contrast, traditional farming techniques increase sunlight and simultaneously UV radiation during plant growth and ripening to increase secondary plant metabolites that contribute to flavor and color, e.g., reduction of leaves in the vine during berry ripening [16,17]. Recent studies, however, have highlighted the regulatory properties of low, ecologically relevant UVB levels that trigger the accumulation of certain flavonoids, known for their high antioxidant activity, in Brassica species [11,18-21] and other species [14,22]. Flavonoid enrichment also affects plant quality and is important in meeting consumer preferences for fruits and vegetables, including growth and appearance, aroma/smell, flavor, color, and compounds that promote plant and human health [14].

In this study, the effect of UV-B treatment on leafy Brassica vegetables is demonstrated by including all six Brassica species reflecting the Brassica $\mathrm{U}$ triangle. The aim was to show the effect of short-term UV-B radiation at the end of the production cycle without affecting plant growth, and to look at the gene expression of enzymes involved in the biosynthesis of flavonoid glycosides and hydroxycinnamic acid derivatives during this period, in order to verify for further studies which exposure time and adaptation period is suitable to use $\mathrm{UV}$ as a biotechnological tool in greenhouse production for different Brassica species.

\section{Results}

Six leafy Brassica species representing the Brassica $U$ triangle were analyzed for their flavonoid glycoside accumulation (Figure 1) after short-term UV-B treatment (Tables S1-S6) at the end of their production cycle as baby leaf salads. In addition, hydroxycinnamic acid derivatives (Figure 1; Table S7) were studied. The effect of UV-B treatment on flavonoid groups and hydroxycinnamic acid derivatives was studied for each Brassica species (Figure 2). Accompanying the metabolites, gene expression of key genes in the phenylpropanoid pathway (Figure 3) was analyzed to specify the role of specific enzymes in the response to UV-B (Figure 4).

\subsection{Flavonoid Glycosides and Hydroxycinnamic Acid Derivatives in Related Brassica Species}

All studied Brassica species (Figure 1) showed high concentrations of acylated kaempferol triglycosides, while some of them also contain remarkable amounts of kaempferol tetraglycosides.

The concentration of quercetin tri- and tetraglycosides was lower compared to the kaempferol tri- and tetraglycosides. However, in the case of diglycosides, which are a minor fraction of flavonoid glycosides in Brassica, the concentrations of quercetin glycosides were higher than those of kaempferol glycosides in B. rapa ssp. chinensis (genome $\mathrm{AA}$ ) and B. juncea (genome AABB). In detail, B. rapa ssp. chinensis was mainly characterized by acylated kaempferol di- and triglycosides, whereas kaempferol or quercetin tetraglycosides were absent. In addition to acylated kaempferol di- and triglycosides, B. nigra (genome BB) contained acylated kaempferol tetraglycosides, whereas corresponding quercetin glycosides were generally absent at higher concentrations. In contrast to the two previously mentioned, B. oleracea var. sabellica (genome CC) contained acylated kaempferol and quercetin di-, tri-, and tetraglycosides, representing the highest diversity of flavonoid glycosides among the Brassica species studied. However, the concentration of flavonoid glycosides in B. oleracea var. sabellica is low compared to the other Brassica species studied. Interestingly, B. juncea has higher concentrations of quercetin diglycosides but lower concentrations of quaercetin triglycosides than B. rapa ssp. chinensis. In general, it contained the highest concentrations of flavonoid glycosides. On the other hand, B. napus (genome AACC) has a lower number of quercetin glycosides while it contains a diversity of 
kaempferol di-, tri-, and tetraglycosides, clearly showing the influence of the B. oleracea var. sabellica. The last species B. carinata (genome BBCC) is characterized by a high diversity of flavonoid glycosides including kaempferol and quercetin di-, tri- and tetraglycosides and therefore is comparable to $B$. oleracea var. sabellica regarding the flavonoid glycoside profile.

Hydroxycinnamic acid derivatives (Figure 1) were highly concentrated in B. rapa ssp. chinensis and B. juncea and B. napus, but low concentrated in the other species not containing the AA genome.

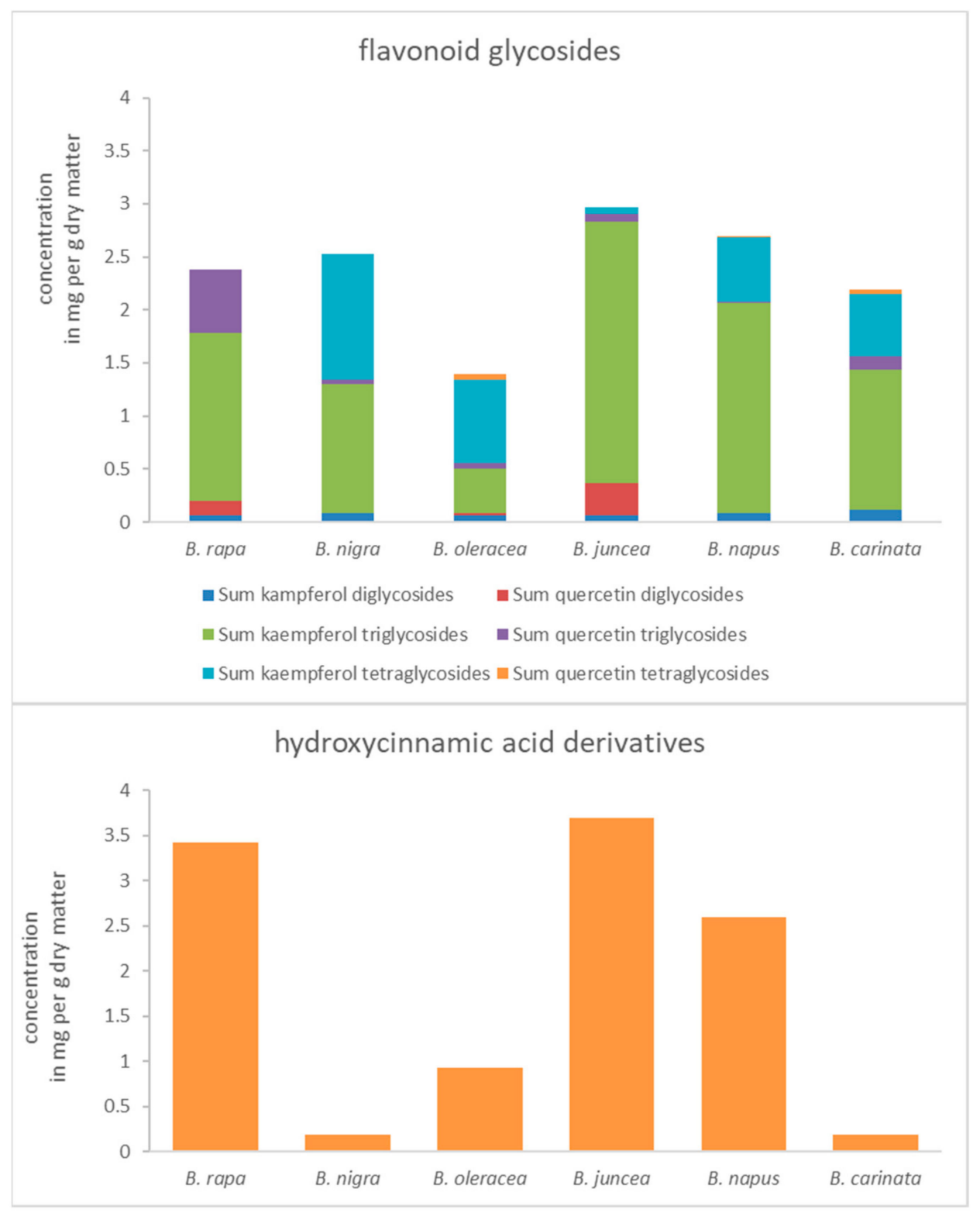

Figure 1. Concentration of flavonoid glycoside groups (separated on the type of aglycone and the glycosylation pattern) and hydroxycinnamic acid derivatives of related Brassica species (mean of all control plants) in mg per g dry matter.

\subsection{The Effect of UV-B, Exposure Time, and Adaptation Time on Flavonoid Glycosides and} Hydroxycinnamic Acid Derivatives in Related Brassica Species

The concentrations of flavonoid glycosides and hydroxycinnamic acid derivatives increased with plant development over the 7 days of the experiment. For most of the species studied, the effect of the UV-B treatment was below $50 \%$ increase or decrease, with some exceptions that depended on species and exposure or adaptation time (Figure 2). While 
kaempferol diglycosides were involved in the early response to UV-B, kaempferol tri- and tetraglycosides were less intensely altered by UV-B in all Brassica species. In contrast, in $B$. oleracea var. sabellica quercetin glycosides generally appear to be the line of defense against UV-B with a dose-response relationship (Figure 2). In B. nigra, B. napus, and B. carinata quercetin tri- and tetralycosides are important for UV-B response on later days. In the results of ANOVA (Tables S1-S7) and subsequent Tukey's HSD (data not shown), mention is made only when both resulted in a significant change.

Kaempferol diglycosides (Table S1) show a species specific response to short-term UV-B among the Brassica species studied. While in B. rapa ssp. chinensis, caffeic acid acylated kaempferol diglycoside was increased after $24 \mathrm{~h}$ of adaptation on day 1 , ferulic acid acylated kaempferol diglycoside was increased on day 7 after 2 and $24 \mathrm{~h}$ of adaptation. In B. nigra, caffeic acid acylated and hydroxyferulic acid acylated kaempferol diglycosides were increased day 1 . Later, no effect of UV-B was found, except for an increase in sinapic acid acylated kaempferol diglycoside after $2 \mathrm{~h}$ of adaptation on day 4 . At the same time, in B. oleracea var. sabellica, B. juncea, and B. napus, hardly any effects of UV-B on kaempferol diglycosides are detectable, whereas in $B$. carinata hydroxyferulic acid acylated kaempferol diglycoside increased after $2 \mathrm{~h}$ of adaptation on day 1 and sinapic acid acylated kaempferol diglycoside after $24 \mathrm{~h}$ of adaptation on day 1. Quercetin diglycosides (Table S2) were not affected by the UV-B treatment regardless of exposure time and adaptation time, except for quercetin-3-sophoroside, which was increased after $2 \mathrm{~h}$ of adaptation on day 7 in B. oleracea var. sabellica.
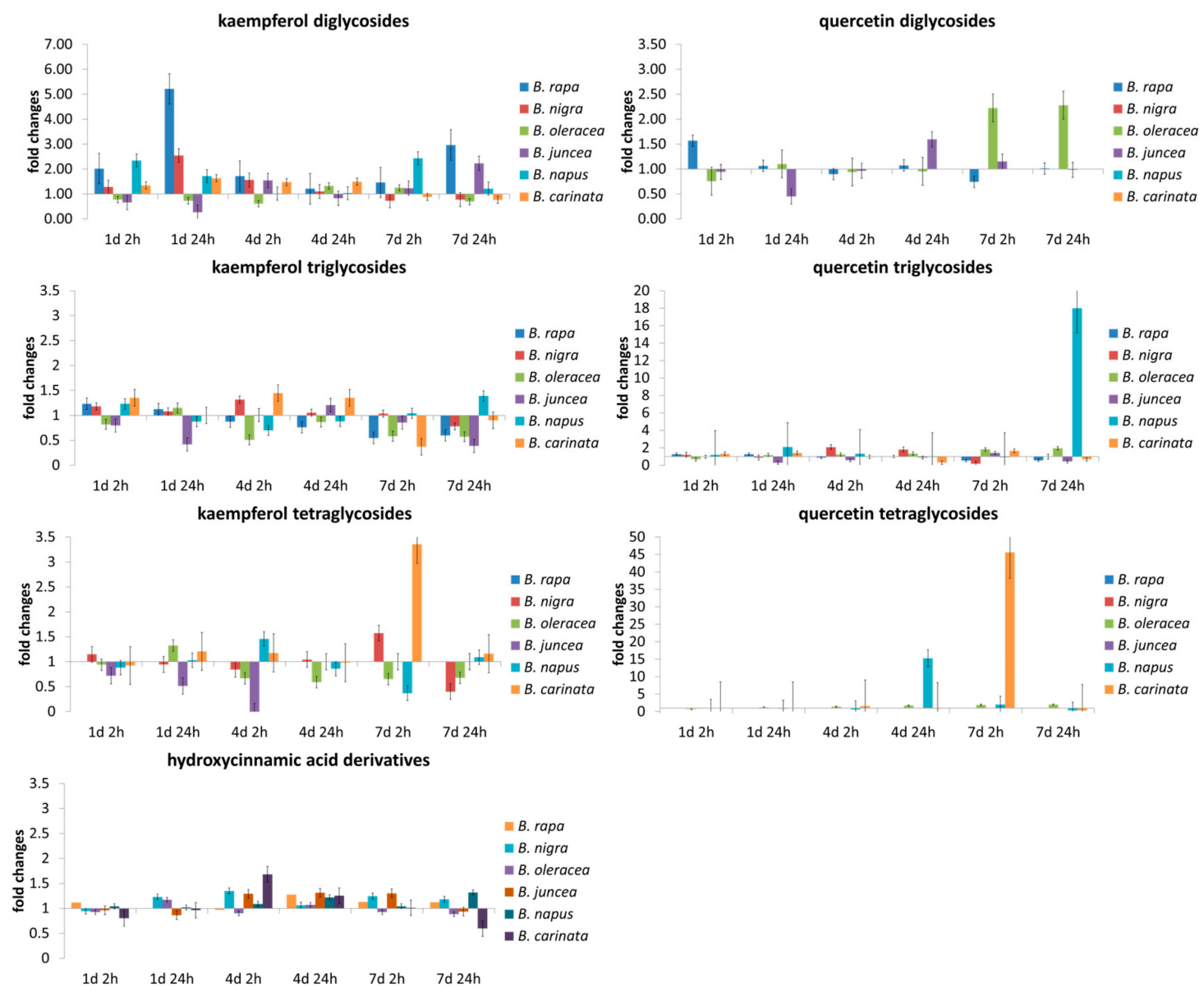

Figure 2. Relative changes in the concentration of flavonoid glycoside groups (separated on the type of aglycone and the glycosylation pattern) and hydroxycinnamic acid derivatives of related Brassica species normalized on the value of the control plants at the certain time points (at days 1, 4, and 7 of the treatment with $2 \mathrm{~h}$ or $24 \mathrm{~h}$ of adaptation time after the last UV treatment). 




Figure 3. Biosynthesis of phenylpropanoids relevant to Brassica species including the involved enzymes PAL: phenylalanine ammonia-lyase, $\mathrm{C} 4 \mathrm{H}$ : cinnamic acid 4-hydroxylase, $\mathrm{C} 3 \mathrm{H}$ : p-coumaric acid 3-hydroxylase, OMT: O-methyltransferase, F5H: ferulic acid 5-hydroxylase, 4CL: 4-Coumaroyl CoA-Ligase CHS: chalcone synthase, CHI: chalcone isomerase, F3H: flavanone $3 \beta$-hydroxylase, FLS: flavonol synthase, F3'H: flavonol 3'-hydroxylase, $3^{\prime}$ OMT: $3^{\prime}-O$-methyltransferase, DFR: dihydroflavonol 4-reductase, ANS: anthocyanin synthase.

The triglycosides of kaempferol and quercetin (Tables S3 and S4) were affected by short-term UV-B treatment not only by species but also as a function chemical structural characteristics including the aglycone and the acylated hydroxycinnamic acid. In $B$. rapa ssp. chinensis, $B$. nigra, and $B$. napus only a small number of kaempferol and quercetin triglycosides were induced at all by the UV-B treatment. However, in B. rapa ssp. chinensis, the ferulic acid acylated kaempferol triglycoside was decreased at day 7 after $2 \mathrm{~h}$ adaptation. Changes were observed in B. nigra towards the beginning of the treatment including the increase of hydroxyferulic acid acylated quercetin triglycoside after $2 \mathrm{~h}$ of adaptation of day 1 followed by the decrease of the same compound after $24 \mathrm{~h}$ of adaptation at day 1 . In contrast to the two before mentioned species, B. oleracea var. sabellica showed a high response of kaempferol and quercetin triglycosides starting after $2 \mathrm{~h}$ of adaptation on day 4 and established on day 7 as evidenced mainly by the decrease of non-acylated and acylated kaempferol glycosides and an increase of coumaric acid acylated kaempferol triglycoside and caffeic acid acylated quercetin triglycoside on day 4 after 2 and $24 \mathrm{~h}$ of adaptation, respectively. The hybrids $B$. juncea and $B$. napus showed a decrease in triglycosides or 
no effects of the UV-B treatment on the kaempferol and quercetin triglycosides, whereas $B$. carinata showed a high response of kaempferol and quercetin triglycosides in the same way as B. oleracea var. sabellica. Interestingly, in B. carinata, non-acylated and acylated kaempferol increased at day 4 mainly at $2 \mathrm{~h}$ of adaptation and quercetin-3-hydroxyferuloylsophoroside-7-glucoside was increased at day 1 regardless of adaptation time, but no effect was found at day 7.

No kaempferol or quercetin tetraglycosides (Tables S5 and S6) were detected in B. rapa ssp. chinensis. No effects were detected for the kaempferol tetraglycosides in B. nigra and the hybrids $B$. juncea and B. napus. However, the tetraglycosides of B. oleracea var. sabellica responded strongly to the short-term UV-B treatment. Most kaempferol tetraglycosides were decreased at day 7 independent of the adaptation time, except the hydroxyferulic acid acylated kaempferol tetraglycoside, which was increased after 2 and $24 \mathrm{~h}$ adaptation on day 7. A higher number of tetraglycosides were identified in B. carinata, of which the sinapic acid acylated kaempferol tetraglycoside increased after $24 \mathrm{~h}$ adaptation on day 4 , whereas the disinapic acid acylated kaempferol tetraglycoside decreased after $24 \mathrm{~h}$ of adaptation on day 7. Quercetin tetraglycosides were not affected by UV-B, with the exception of quercetin3-sinapoyl-sohoroside-7-diglucoside, which was increased in B. oleracea var. sabellica at days 4 and 7 regardless of the adaptation time.

The effect of UV-B on hydroxycinnamic acid derivatives (Table S7) was investigated. B. nigra, B. oleracea var. sabellica, and B. carinata contain the typical hydroxycinnamic acid derivatives chlorogenic acid, disinapoyl-gentionbioside and sinapoyl, feruloylgentiobioside, trisinapoyl-gentiobioside and disinapoyl, feruloyl-gentiobioside. In B. nigra, only cholorogenic acid was used in early UV-B defense, resulting in an increase on day 1 after $2 \mathrm{~h}$ of adaptation. B. oleracea var. sabellica trisinapoyl-gentiobiose was increased on day 4 and day 7 after 2 h of adaptation, while disinapoyl, feruloyl-gentiobiose was increased on day 4 after $2 \mathrm{~h}$ of adaptation only. In agreement with this, in B. carinata disinapoyl-gentibioside and trisinapoyl-gentiobioside were increased on day 4 regardless of the adaptation time and the latter one was also increased on day 7 at $24 \mathrm{~h}$ of adaptation. At the same time, cholorogenic acid was decreased after $2 \mathrm{~h}$ of adaptation on day 7. B. rapa ssp. chinensis, $B$. juncea, and B. napus were able to synthesize hydroxycinnamoly malates and preferentially used them in the UV-B response. In B. rapa ssp. chinensis, cholorgenic acid decreased after $2 \mathrm{~h}$ of adaptation on day 4 and hydroxyferuloyl malat decreased after $24 \mathrm{~h}$ of adaptation on the same day, whereas in B. juncea coumaroyl malate, feruloyl malate, and sinapoyl malate increased after $24 \mathrm{~h}$ of adaptation on day 4 . In parallel, in B. napus coumaroyl malate and sinapoyl malate increased after $24 \mathrm{~h}$ of adaption on day 4 , with sinapoyl malate already enhanced after $2 \mathrm{~h}$ of adaptation.

\subsection{The Effect of UV-B, Exposure Time and Adaptation Time on Gene Expression in Related Brassica Species}

In all Brassica species, the gene expression of enzymes (Figure 3) included in flavonoids synthesis tended to be reduced or unaffected by UV-B treatment, reflecting marginal changes in flavonoid glycosides (Figure 4).

In $B$. rapa ssp. chinensis, a downregulation of $P A L$ gene as key enzyme of flavonoid synthesis was found $24 \mathrm{~h}$ after UV-B treatment on day 4. Comparably, in B. carinata, an induction of PAL was observed $2 \mathrm{~h}$ after UV-B treatment on day 4 as early reaction that was downregulated after $24 \mathrm{~h}$. Most Brassica species show a decrease of $4 C L$ gene right at the beginning on day 1 after $2 \mathrm{~h}$ of adaptation. In B. rapa ssp. chinensis, B. oleracea var. sabellica and $B$. juncea a constant reduction of $4 C L$ gene was found with some exceptions. Similarly, the expressions of $F 3 H$ and FLS genes were reduced in B. oleracea var. sabellica and B. juncea but not in $B$. rapa ssp. chinensis. F3' $H$ gene mRNA expression was downregulated after adaptation to UV-B on day 4 after $24 \mathrm{~h}$ in B. carinata after early induction at day 1 after $2 \mathrm{~h}$, whereas in B. oleracea var. sabellica and B. napus $F 3^{\prime} H$ gene was induced at day 7 after $2 \mathrm{~h}$ and $24 \mathrm{~h}$, respectively. In both species, quercetin glycosides were simultaneously increased at the corresponding time points (Figure 4). 






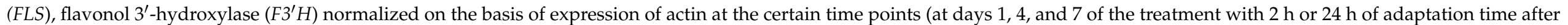
the last UV treatment). Significant differences are highlighted by an asterix at $p \leq 0.05$. 


\section{Discussion}

Leafy Brassica species are a rich source of structurally different flavonoid glycosides, especially high complex kaempferol and quercetin tri- and tetraglycosides. This is generally confirmed in the literature for B. rapa ssp. chinensis [3], B. nigra [23], B. oleracea var. sabellica [24-27], B. juncea [28,29], B. napus [27,30-32], and B. carinata [12]. Therefore, they are suitable for human consumption and recently gained attention as raw salads.

\subsection{The Effect of UV-B on Flavonoid Glycosides in Related Brassica Species}

Flavonoids are known to be enhanced by UV-B radiation as a part of the plant's defense and by aging of the plant [33]. Here B-ring poly-hydroxylated compounds such as quercetin are favored in the UV-B response over B-ring mono-hydroxylated compounds such as kaempferol [34]. The results shown here, in contrast, underline previous results on B. oleracea var. sabellica $[20,35]$ that the response to UV-B is dependent on the chemical structure of the compound and the duration of the UV-B treatment as well as the adaptation time. It can be concluded that kaempferol glycosides also contribute to the UV-B response, which was previously reported for B. rapa ssp. chinensis [18], B. oleracea var. sabellica [20] and B. napus [11]. However, the present results were conducted under 2-6 fold higher PAR conditions and also higher temperature than the previous study on B. oleracea var. sabellica [20], which clearly had an effect on the flavonoid biosynthesis and led to remarkably lower concentrations of quercetin and kaempferol glycosides in the present experiment. The present experiment shows that quercetin glycosides are not always preferred over kaempferol glycosides, as exemplified for B. rapa ssp. chinensis, where UV-B treatment generally had a minor effect. However, some species seem to prefer quercetin glycosides over kaempferol glycosides, such as B. oleracea var. sabellica or B. carinata, both of which showed similar response to UV-B and carry the CC genome. This has already been shown for B. oleracea var. sabellica in previous studies [20]. In the present study, B. napus did not show high concentrations of quercetin glycosides and did not induce the concentrations of quercetin glycosides due to the UV-B treatment, which is in contrast to the results of Olsson et al. 1998 [11], who used much higher doses of UV-B in the greenhouse. A catechol structure is also found in the acylated hydroxycinnamic acid of the flavonoid glycoside. While caffeic acid and hydroxyferulic acid have a catechol structure, coumaric acid, ferulic acid, and sinapic acid do not. This does not necessarily reflect their ability as antioxidants [36]. The antioxidant activity of compounds including sinapic acid may be remarkable [36]. This is supported by the fact that most Brassica species, including B. nigra, B. oleracea var. sabellica, B. juncea, and B. carinata also increase sinapic acid acylated kaempferol or quercetin glycosides in response to UV-B while B. rapa ssp. chinensis and $B$. napus, both of which carry the AA genome, do not. However, Harbaum-Piayda et al. 2010 [18] showed an increase in non-acylated and coumaric acid acylated kaempferol triglycosides in B. rapa ssp. chinensis at $22{ }^{\circ} \mathrm{C}$ after 7 days of UV-B treatment, but with higher doses of UV-B at very low PAR. In general, it is known that the intensity of the UV-B doses can be percieved by plants [37] and that the UV/PAR ratio also affects the efficiency of the UV-B exposure $[38,39]$. In the present experiment, the UV-B dose was low and the PAR was ambient sunlight, which is relatively high. This is one of the challenges transferring the results on UV-B obtained from climate chamber experiments to greenhouses for use as biotechnological tool. While B. oleracea var. sabellica, B. juncea, and B. carinata show a higher response of kaempferol glycosides acylated with a hydroxycinnamic acid including a catechol structure, this was not the case for the other Brassica species. The catechol structure not only in the flavonoid aglycone but also in the acylated hydroxycinnamic acid is associated with higher antioxidant activity, but there might be interactions within the molecule [36].

\subsection{The Effect of UV-B on Hydroxycinnamic Acid Derivatives in Related Brassica Species}

Hydroxycinnamic acid derivatives from Brassica species [40] have rarely been studied as UV-B protectants. The representative hydroxycinnamic acids of Brassica are chloro- 
genic acid, disinapoyl-gentionbioside and sinapoyl, feruloyl-gentiobioside, trisinapoylgentiobioside, and disinapoyl, feruloyl-gentiobioside $[3,4,25]$. In addition to those previously mentioned, B. rapa ssp. chinensis, B. juncea, and B. napus, all of which contain the genome AA, are capable of synthesizing malates of hydroxycinnamic acids $[3,28,30]$. In the present study, the hydroxycinnamic acid malates of B. rapa ssp. chinensis were not intensively used for UV-B response, which is consistent with results from Harbaum-Piayda et al. 2010 [18], who found no effect of UV-B at $22{ }^{\circ} \mathrm{C}$ in B. rapa ssp. chinensis. However, these compounds seem to play a crucial role in the UV-B response of $B$. juncea and B. napus. In B. nigra, B. oleracea var. sabellica, and $B$. carinata chlorogenic acid and the sinapic acid acylated glycosides take over the response to UV-B, although no effects of UV-B treatment on these compounds were previously described in B. oleracea var. sabellica [20].

\subsection{The Effect Exposure Time and Adaptation Time on Flavonoid Glycosides and Hydroxycinnamic Acid Derivatives in Related Brassica Species}

The species also differ in their temporal response. While B. rapa ssp. chinensis, B. nigra, $B$. napus, and B. carinata show an immediate positive response and $B$. juncea shows a negative response starting on day 1 but lasting only until day 4 , B. oleracea var. sabellica has a delayed response starting on day 4 and continuing until day 7 . The duration of the UV-B treatment is one of the major challenges in implementing this technique into greenhouses [14]. While some studies show an adaptation of plants within $h[41,42]$ other studies indicate that constant UV-B treatment over a longer period is required [43-46]. In particular, an increase in flavonoids after several UV-B treatments over several days has been reported in the literature, as shown for Arabidopsis thaliana, a model plant and relative of Brassica [47], such as Brassica oleracea var. sabellica [20]. An increase in sinapoyl, feruloyl-gentiobiose after $24 \mathrm{~h}$ adaptation as well as trisinapoyl-gentiobiose and disinapoyl, feruloyl-gentiobiose at day 4 was found in the present study for B. oleracea var. sabellica and previously an increase in these compounds in response to UV-B at high PAR was described for B. oleracea var. italica [48]. The present study highlights that in Brassica species, the effect of UV-B is highly dependent on the species itself. Therefore, tailored UV radiation recipes need to be developed separately for each species, especially when a UV-B treatment is considered at the end of the production cycle. A second aspect was investigated in the present study, which is the adaptation time. In A. thaliana, it was shown that a higher number of genes were affected by high light treatment after $24 \mathrm{~h}$ then after $2 \mathrm{~h}$ [49]. Higher light treatment was also associated with higher concentrations of kaempferol glycosides in A. thaliana [50] The present study suggests that there are fast responding species that increase their quercetin glycosides within $2 \mathrm{~h}$ of adaptation, such as B. oleracea var. sabellica and B. carinata, while in others biosynthesis is slower, resulting in changes after 24 h, e.g., in the hybrid B. napus.

\subsection{The Effect of UV-B, Exposure Time, and Adaptation Time on Gene Expression in Related Brassica Species}

In general, the gene expression results represent the findings for flavonoid glycosides. In some species such as $B$. juncea and B. napus gene expression was comparable across the exposure time and adaptation time, highlighting the small effect the UV-B treatment had on these plants. On the other hand, species such as B. rapa var. chinensis, B. oleracea var. sabellica and B. carinata showed that gene expression was altered over both the exposure time as well as the adaptation time. This demonstrates how rapidly and specifically some Brassica species can adapt their flavonoid profile and concentration as needed. Although downstream gene expression starting at PAL and including $4 \mathrm{CL}, \mathrm{F} 3 \mathrm{H}$, and $\mathrm{F}^{\prime} \mathrm{H}$ has been proposed in $A$. thaliana [51], present data highlight that specific gene expression occurs in response to UV-B by increasing $\mathrm{F}^{\prime} \mathrm{H}$ specifically in B. oleracea var. sabellica, B. napus, and $B$. carinata. The complexity of gene expression in relation to flavonoid biosynthesis was previously shown in $A$. thaliana by combining intrinsic and extrinsic factors [52]. The importance of flavonols such as quercetin and kaempferol in the absorption of UV and blue light was shown in A. thaliana mutants (tt5-CHI) and to their absence resulted in higher 
damage in the chloroplast [53]. However, the expression of PAL, 4CL, F3H, and FLS was mostly downregulated in the Brassica species, which may be a feedback to the high $\mathrm{F}^{\prime} \mathrm{H}$ gene expression or a consequence of the high concentrations of kaempferol glycosides already present in Brassica species, sufficient for the UV response. However, F3'H gene expression was increased in B. oleracea var. sabellica and B. carinata, which simultaneously resulted in higher concentrations of quercetin glycosides, whereas it was hardly affected in other Brassica species. This supports the results of the metabolite analysis showing that $B$. oleracea var. sabellica and B. carinata favor quercetin quercetin glycosides in the response to UV-B, while the other Brassica species do not. The decrease of $4 \mathrm{CL}$ gene expression did not necessarily lead to higher concentrations of hydroxycinnamic acid derivatives, as exemplified in B. oleracea var. sabellica. While B. rapa var. chinensis is a species grown in the subtropics and tropics, $B$. oleracea var. sabellica is an established vegetable grown in winter in Central Europe. These different growing conditions may have influenced the sesitivity to reactive oxygen species and the ability of the plant to synthesize flavonoid glycosides and hydroxycinnamic acid derivatives as defense compounds.

\section{Materials and Methods}

\subsection{Plant Material and Experimental Design}

Seeds of Brassica rapa ssp. chinensis (pak choi) cv Black Behi (By Allied Botanical, Quezon City, Philippines), Brassica oleracea var. sabellica (kale) cv Winterbor (by Bruno Nebelung, Norken, Germany), Brassica juncea cv Mizuna, Brassica napus und Brassica nigra (all by Albert Treppens \& Co Samen GmbH, Berlin, Germany), and Brassica carinata (by the World Vegetable Center (AVRDC) Arusha, Tanzania) were sown on 9 September 2016 in potting soil (Einheitserde Type 1, Fitz Kausek GmbH \& Co.KG, Mittenwalde, Germany) and set in a randomized block. Water was supplied as required by the plants and fertilizer was administered every two weeks as a nutrient solution $\left(\mathrm{pH} 6.4, \mathrm{P}_{1} \mathrm{mg} \mathrm{L}^{-1}\right.$, $\mathrm{Mg} 43 \mathrm{mg} \mathrm{L}^{-1}, \mathrm{NO}_{3} 154 \mathrm{mg} \mathrm{L}^{-1}$, Ca $205 \mathrm{mg} \mathrm{L}^{-1}, \mathrm{~K}_{230 \mathrm{mg} \mathrm{L}}^{-1}, \mathrm{SO}_{4} 280 \mathrm{mg} \mathrm{L}^{-1}$, Zn $\left.0.82 \mathrm{mg} \mathrm{L}^{-1}\right)$. All plants were grown to the $4-5$ leaf stage under greenhouse conditions (temperature $20{ }^{\circ} \mathrm{C}$ and PAR mean $603 \mu \mathrm{mol} \mathrm{m}{ }^{-2} \mathrm{~s}^{-1}\left(82-1167 \mu \mathrm{mol} \mathrm{m}^{-2} \mathrm{~s}^{-1}\right)$ ) in Grossbeeren (Germany, $52.37^{\circ} \mathrm{N} 13.33^{\circ} \mathrm{E}$ ) under partly cloudy skies. Plants were exposed to up to seven consecutive daily doses of $0.5 \mathrm{~kJ} \mathrm{~m}^{-2} \mathrm{~d}^{-1} \mathrm{UV}-\mathrm{B}$ radiation $(1 \mathrm{~h} \mathrm{UV-B}$ (10:00 to 11:00) with acclimation intervals of $23 \mathrm{~h}$ ), which corresponds to a daily dose of one winter day in central Europe [54] and is thus moderate among the PAR doses used. This daily dose was previously applied to greenhouse-grown kale and resulted in an increase in quercetin glycosides after 3 or more days of exposure [20]. UV-B radiation was supplied by five UV-B fluorescent light sources (TL 40W 12 RS, Philips, Hamburg, Germany) and the distance of the UV-B lamps to the plants was $80 \mathrm{~cm}$. UV-B radiation was determined using a UV-B sensor (type DK-UVB 1.3-051, deka Sensor + Technologie, Teltow, Germany) with a spectral range of 265 to $315 \mathrm{~nm}$. The corresponding biologically effective UV-B irradiance of $0.25 \mathrm{~kJ} \mathrm{~m}^{-2} \mathrm{~d}^{-1} \mathrm{UV}-\mathrm{B}_{\mathrm{BE}}$ was calculated using Caldwell's generalized plant weighting function. Two plants per replicate and three biological replicates per treatment were harvested from the plant block on days 1, 4, and 7 after an acclimation period of $2 \mathrm{~h}$ or $24 \mathrm{~h}$ after UV-B treatment.

\subsection{Sample Preparation}

Leaves (without midrib) were collected from three plants at the 4- to 5-leaf stage and frozen in liquid nitrogen. One aliquot was stored at $-80{ }^{\circ} \mathrm{C}$ for gene expression analysis, and one aliquot was stored at $-40^{\circ} \mathrm{C}$ until lyophilization, lyophilized, and then ground to a powder. Samples were stored in the dark at room temperature until needed for analysis. For analysis of flavonol glycosides, samples were extracted as previously described [12].

\subsection{HPLC-DAD-ESI-MS}

The HPLC-DAD-ESI-MS ${ }^{n}$ method for the tentative identification and quantitation of the flavonol glycosides in Brassica species was done with an HPLC series 1100 by Agilent 
(Waldbronn, Germany) consisting of a degaser, binary pump, autosampler, column oven, and photodiode array detector was used. An ion trap (Agilent series 1100 MSD) with an ESI ion source in negative ionization mode was used as the mass spectrometer. The parameters for the HPLC-DAD-ESI-MS ${ }^{n}$ were formerly described [35]. Mass fragments for the identification of the compounds were previously given [26]. The standards quercetin3-O-glucoside (for quercetin glycosides) and kaempferol-3-O-glucoside (for kaempferol glycosides) were used to obtain an external calibration curve ranging from 0.1 to $10 \mathrm{mg}$ $100 \mathrm{~mL}^{-1}$ for a semi-quantitative approach.

\subsection{Gene Expression Analysis by Semi-Quantitative Real-Time PCR}

RNA was extracted from an aliquot $(10 \mathrm{mg})$ of the identical plant material as used for the metabolite analysis using the Nucleo-Spin Plant Kit (Macherey-Nagel GmbH and Co. KG, Dueren Germany), including on-column DNase digestion. RNA was quantified spectrophotometrically at $260 \mathrm{~nm}$ (NanoDrop ND1000, NanoDrop Technology Inc., Wilmington, DE, USA); quality was checked using the A 260/A 280 ratio calculation, whereby a ratio between 1.9 and 2.1 was considered acceptable. Single-stranded cDNA synthesis was carried out with total RNA using SuperScript_ III RNaseHreverse transcriptase (Invitrogen $\mathrm{GmbH}$, Darmstadt, Germany) with oligo d(T12-18) primers according to the manufacturer's instructions. Quantitative two-step RT-PCR was performed using an SYBR Green ${ }^{\circledR}$ protocol in 96-well reaction plates on an Applied Biosystems 7500 Real-time PCR System. The following thermal profile was used for all reactions: $50{ }^{\circ} \mathrm{C}$ for $2 \mathrm{~min}, 95{ }^{\circ} \mathrm{C}$ for $10 \mathrm{~min}, 40$ cycles of $95^{\circ} \mathrm{C}$ for $30 \mathrm{~s}$, and $60^{\circ} \mathrm{C}$ for $1 \mathrm{~min}$, followed by dsDNA melting curve analysis to ensure amplicon specificity. Each reaction was performed in a $10 \mu \mathrm{L}$ volume containing $200 \mathrm{nM}$ of each primer, $3 \mu \mathrm{L}$ of cDNA (1:50), and $7 \mu \mathrm{L}$ of Power SYBR Green Master Mix (Applied Biosystems, Foster City, CA, USA). The gene-specific primer sets are listed in Table 1.

Table 1. Oligonucleotide primers for genes of the phenolprpanoid biosynthesis and the reference gene based on the genome of Brassica oleracea for gene expression analysis by semiquantitative real-time PCR.

\begin{tabular}{|c|c|c|}
\hline $\begin{array}{l}\text { Gene Function } \\
\text { (Gene Name) }\end{array}$ & $\begin{array}{l}\text { Oligonucleotide } \\
\text { Abbreviation }\end{array}$ & Sequence \\
\hline \multirow[t]{2}{*}{$\operatorname{Actin}(A C T)$} & Bo_ACT2_up1_E4 & GCA-CCT-CCC-GAG-AGG-AAG-TA \\
\hline & Bo_ACT2_lo1_E4/5 & CCT-TGG-AGA-TCC-ACA-TCT-GCT \\
\hline \multirow[t]{2}{*}{ Phenylalanine ammonium lyase $(P A L)$} & Bo-up 1 PAL E1 & TGG-GTT-ATG-GAA-AGT-ATG-GGC-A \\
\hline & Bo-lo 1 PAL E1-2 & CCG-GCG-TTC-AAA-AAT-CTG-ATG-A \\
\hline \multirow[t]{2}{*}{ 4-coumaroyl CoA ligase $(4 C L)$} & Bo-up_4CL_E3/4 & CCT-TGG-CCA-GGG-ATA-TGG-TA \\
\hline & Bo-lo_4CL_E4 & AGC-TCT-GCG-TTT-CGG-ACT-AC \\
\hline \multirow[t]{2}{*}{$\begin{array}{l}\text { Flavanone } 3 \beta \text {-Hydroxylase } \\
\qquad(F 3 H)\end{array}$} & Bo_F3H_up1_E2/3 & TCC-ACC-TGA-GTA-CAG-AGA-GGT \\
\hline & Bo_F3H_lo1_E3 & TTC-TCT-CAA-CGC-CTC-ACG-AC \\
\hline \multirow[t]{2}{*}{ Flavonol synthase $(F L S)$} & Bo-up 6 FLS E2-3 & CGG-CGA-TCA-GAT-ACT-GAG-GCT \\
\hline & Bo-lo 6 FLS E3 & TGT-GGC-TCC-AAG-AAC-ACT-GG \\
\hline \multirow[t]{2}{*}{ Flavonol $3^{\prime}$-hydroxylase $\left(F 3^{\prime} H\right)$} & Bo ᄀ_F3'H_up2_E3/4 & CCG-TAC-CTT-CAG-GCG-GTT-AT \\
\hline & Bo $\neg$ F3'H_lo2_E4 & AGC-CGT-TGA-TCT-CAC-AGC-TC \\
\hline
\end{tabular}

Design of primer pairs for amplification of mRNA regions including one exonjunction was performed using NCBI reference sequences predicted for Brassica oleracea flavonoid synthesizing enzymes: XM_013749252.1 for PAL phenylalanin ammonia lyse 2 (LOC106311920), XM_01373510.1 for 4CL 4-coumarate-CoA ligase 3 (LOC106296384), XM_013778875.1 for ANS anthocyanidin synthase (LOC106339986), XM_013753582.1 for DFR Dihydroflavonol-4-reductase or leucoanthocyanidin dioxygenase LDOX (LOC106315758), XM_013758739.1 for FLS3 flavonol synthase 3-like (LOC 106320382), XM_013751217.1 for F3H flavanone 3-hydroxylase (LOC 106313418), XM_013751545.1 for F3'H flavonoid 3'monooxygenase (LOC106313667), and XM_013753106.1 for housekeeping gene actin-2 (LOC 106315376). Data generated by real-time PCR were collected and compiled using 
7500 v2.0.1 software (Applied Biosystems). Data were exported to LinReg software [54] to determine the PCR amplification efficiency for each primer pair. Relative transcript levels were normalized on the basis of expression of an invariant control orthologous to actin-2 using the equation $2^{-\Delta \Delta C T}$ [55]. Quantitative PCR was performed on three biological replicates measured in duplicates for each gene; non-template controls were included.

\subsection{Statistical Analysis}

All data were statistically analyzed with two-way ANOVA followed by Tukey's HSD test for selected compounds. Residuals were tested for Gaussian distribution using the Kolmogorov-Smirnov test. All tests were performed at a 5\% significance level. Calculations were performed using StatisticaTM for WindowsTM (version 9.0, Statsoft Inc., Tulsa, OK, USA).

\section{Conclusions}

Leafy Brassica species, especially B. oleracea var. sabellica and B. carinata, are a suitable target for the implementation of UV-B radiation into greenhouses. It is possible to modify their flavonoid glycoside and hydroxycinnamic acid derivative profile by increasing compounds that seem to have potentially high antioxidant activity. However, the response to a short-term UV-B treatment is species specific and conclusions on exposure time and adaptation time need to be drawn separately for each species. Nevertheless, species sharing the same genome are able to synthesize the same compounds and showed similar responses in some cases. For B. oleracea var. sabellica and B. carinata, the exposure time should be 4 days or more, whereas the adaptation time seems to be different between compounds without clear direction. Other environmental factors, especially PAR present during greenhouse production, should also be included to study the interactions.

Supplementary Materials: The following are available online, Table S1: Kaempferol diglycosides of different Brassica species in $\mu \mathrm{g} / \mathrm{g}$ DW., Table S2: Quercetin diglycosides of different Brassica species in $\mu \mathrm{g} / \mathrm{g}$ DW., Table S3: Kaempferol triglycosides of different Brassica species in $\mu \mathrm{g} / \mathrm{g}$ DW., Table S4: Quercetin triglycosides of different Brassica species in $\mu \mathrm{g} / \mathrm{g}$ DW., Table S5: Kaempferol tetraglycosides of different Brassica species in $\mu \mathrm{g} / \mathrm{g}$ DW., Table S6: Quercetin tetraglycosides of different Brassica species in $\mu \mathrm{g} / \mathrm{g}$ DW., Table S7: Quercetin tetraglycosides of different Brassica species in $\mu \mathrm{g} / \mathrm{g}$ DW.

Author Contributions: Conceptualization, S.N. and C.B.-V.; methodology, S.N. and C.B.-V.; software, C.B.-V.; validation, S.N. and C.B.-V.; formal analysis, S.N. and C.B.-V.; investigation, S.N. and C.B.-V.; resources, S.N.; data curation, S.N. and C.B.-V.; writing—original draft preparation, S.N.; writing-review and editing, S.N and C.B.-V.; visualization, S.N.; project administration, S.N.; funding acquisition none. All authors have read and agreed to the published version of the manuscript.

Funding: This research received no external funding. Budget Leibniz-Institute of Vegetable and Ornamental Crops. We acknowledge support by the Open Access Publication Funds of the Göttingen University.

Institutional Review Board Statement: Not applicable.

Informed Consent Statement: Not applicable.

Data Availability Statement: The data presented in this study are openly available at https://data. goettingen-research-online.de/ dataset.xhtml?persistentId=doi:10.25625/JBWKIL.

Acknowledgments: We thank Andrea Maikath and Sarah Farrherr for excellent technical support with the analysis of gene expression and flavonoid analysis, respectively.

Conflicts of Interest: The authors declare no conflict of interest.

Sample Availability: Samples are available from the authors. 


\section{References}

1. Schreiner, M.; Korn, M.; Stenger, M.; Holzgreve, L.; Altmann, M. Current understanding and use of quality characteristics of horticulture products. Sci. Hortic. 2013, 163, 63-69. [CrossRef]

2. Mierziak, J.; Kostyn, K.; Kulma, A. Flavonoids as important molecules of plant interactions with the environment. Molecules 2014, 19, 16240-16265. [CrossRef]

3. Harbaum, B.; Hubbermann, E.M.; Wolff, C.; Herges, R.; Zhu, Z.; Schwarz, K. Identification of flavonoids and hydroxycinnamic acids in pak choi varieties (Brassica campestris L. ssp chinensis var. communis) by HPLC-ESI-MSn and NMR and their quantification by HPLC-DAD. J. Agric. Food Chem. 2007, 55, 8251-8260. [CrossRef]

4. Cartea, M.E.; Francisco, M.; Soengas, P.; Velasco, P. Phenolic compounds in Brassica vegetables. Molecules 2011, 16, 251-280. [CrossRef]

5. Mageney, V.; Neugart, S.; Albach, D.C. A guide to the variability of flavonoids in Brassica oleracea. Molecules 2017, 22, 252. [CrossRef]

6. Zietz, M.; Weckmuller, A.; Schmidt, S.; Rohn, S.; Schreiner, M.; Krumbein, A.; Kroh, L.W. Genotypic and climatic influence on the antioxidant activity of flavonoids in kale (Brassica oleracea var. sabellica). J. Agric. Food Chem. 2010, 58, 2123-2130. [CrossRef]

7. Agati, G.; Brunetti, C.; Di Ferdinando, M.; Ferrini, F.; Pollastri, S.; Tattini, M. Functional roles of flavonoids in photoprotection -new evidence, lessons from the past. Plant Physiol. Biochem. 2013, 72, 35-45. [CrossRef]

8. Chen, A.Y.; Chen, Y.C. A review of the dietary flavonoid, kaempferol on human health and cancer chemoprevention. Food Chem. 2013, 138, 2099-2107. [CrossRef]

9. Bumke-Vogt, C.; Osterhoff, M.A.; Borchert, A.; Guzman-Perez, V.; Sarem, Z.; Birkenfeld, A.L.; Bähr, V.; Pfeiffer, A.F.H. The Flavones Apigenin and Luteolin Induce FOXO1 Translocation but Inhibit Gluconeogenic and Lipogenic Gene Expression in Human Cells. PLoS ONE 2014, 9, e104321. [CrossRef]

10. Pan, M.H.; Lai, C.S.; Ho, C.T. Anti-inflammatory activity of natural dietary flavonoids. Food Funct. 2010, 1, 15-31. [CrossRef]

11. Olsson, L.C.; Veit, M.; Weissenbock, G.; Bornman, J.F. Differential flavonoid response to enhanced UV-B radiation in Brassica napus. Phytochemistry 1998, 49, 1021-1028. [CrossRef]

12. Neugart, S.; Baldermann, S.; Ngwene, B.; Wesonga, J.; Schreiner, M. Indigenous leafy vegetables of Eastern Africa-A source of extraordinary secondary plant metabolites. Food Res. Int. 2017, 100, 411-422. [CrossRef]

13. Jansen, M.A.K.; Bornman, J.F. UV-B radiation: From generic stressor to specific regulator. Physiol. Plant. 2012, 145, 501-504. [CrossRef]

14. Neugart, S.; Schreiner, M. UVB and UVA as eustressors in horticultural and agricultural crops. Sci. Hortic. 2018. [CrossRef]

15. Wargent, J.J.; Jordan, B.R. From ozone depletion to agriculture: Understanding the role of UV radiation in sustainable crop production. New Phytol. 2013, 197, 1058-1076. [CrossRef]

16. Diago, M.P.; Ayestarán, B.; Guadalupe, Z.; Garrido, Á.; Tardaguila, J. Phenolic composition of Tempranillo wines following early defoliation of the vines. J. Sci. Food Agric. 2012, 92, 925-934. [CrossRef]

17. Pastore, C.; Zenoni, S.; Fasoli, M.; Pezzotti, M.; Tornielli, G.B.; Filippetti, I. Selective defoliation affects plant growth, fruit transcriptional ripening program and flavonoid metabolism in grapevine. BMC Plant Biol. 2013, 13, 30. [CrossRef]

18. Harbaum-Piayda, B.; Walter, B.; Bengtsson, G.B.; Hubbermann, E.M.; Bilger, W.; Schwarz, K. Influence of pre-harvest UV-B irradiation and normal or controlled atmosphere storage on flavonoid and hydroxycinnamic acid contents of pak choi (Brassica campestris L. ssp chinensis var. communis). Postharvest Biol. Technol. 2010, 56, 202-208. [CrossRef]

19. Tohidi-Moghadam, H.R.; Ghooshchi, F.; Jamshidpour, F.; Zahedi, H. Effect of UV radiation and elevated $\mathrm{CO}_{2}$ on physiological attributes of canola (Brassica napus L.) grown under water deficit stress. Pol. J. Environ. Stud. 2012, 21, 1417-1427.

20. Neugart, S.; Fiol, M.; Schreiner, M.; Rohn, S.; Zrenner, R.; Kroh, L.W.; Krumbein, A. Interaction of moderate UV-B exposure and temperature on the formation of structurally different flavonol glycosides and hydroxycinnamic acid derivatives in Kale (Brassica oleracea var. sabellica). J. Agric. Food Chem. 2014, 62, 4054-4062. [CrossRef]

21. Rechner, O.; Neugart, S.; Schreiner, M.; Wu, S.; Poehling, H.-M. Can narrow-bandwidth light from UV-A to green alter secondary plant metabolism and increase Brassica plant defenses against aphids? PLoS ONE 2017, 12, e0188522. [CrossRef]

22. Jansen, M.A.K.; Hectors, K.; O’Brien, N.M.; Guisez, Y.; Potters, G. Plant stress and human health: Do human consumers benefit from UV-B acclimated crops? Plant Sci. 2008, 175, 449-458. [CrossRef]

23. Aguinagalde, I. Flavonoids in Brassica nigra (L.) Koch, B. oleracea L., B. campestris L. and their natural amphidiploids. Bot. Mag. 1988, 101, 55-60. [CrossRef]

24. Ferreres, F.; Fernandes, F.; Oliveira, J.M.A.; Valentão, P.; Pereira, J.A.; Andrade, P.B. Metabolic profiling and biological capacity of Pieris brassicae fed with kale (Brassica oleracea L. var. acephala). Food Chem. Toxicol. 2009, 47, 1209-1220. [CrossRef]

25. Olsen, H.; Aaby, K.; Borge, G.I.A. Characterization and quantification of flavonoids and hydroxycinnamic acids in curly kale (Brassica oleracea L. convar. acephala var. sabellica) by HPLC-DAD-ESI-MSn. J. Agric. Food Chem. 2009, 57, 2816-2825. [CrossRef]

26. Schmidt, S.; Zietz, M.; Schreiner, M.; Rohn, S.; Kroh, L.W.; Krumbein, A. Identification of complex, naturally occurring flavonoid glycosides in kale (Brassica oleracea var. sabellica) by high-performance liquid chromatography diode-array detection/electrospray ionization multi-stage mass spectrometry. Rapid Commun. Mass Spectrom. 2010, 24, 2009-2022. [CrossRef]

27. Velasco, P.; Francisco, M.; Moreno, D.A.; Ferreres, F.; Garcia-Viguera, C.; Elena Cartea, M. Phytochemical fingerprinting of vegetable Brassica oleracea and Brassica napus by simultaneous identification of glucosinolates and phenolics. Phytochem. Anal. 2011, 22, 144-152. [CrossRef] 
28. Lin, L.-Z.; Sun, J.; Chen, P.; Harnly, J. UHPLC-PDA-ESI/HRMS/MSn Analysis of Anthocyanins, Flavonol Glycosides, and Hydroxycinnamic Acid Derivatives in Red Mustard Greens (Brassica juncea Coss Variety). J. Agric. Food Chem. 2011, 59, 12059-12072. [CrossRef]

29. Kim, J.E.; Jung, M.J.; Jung, H.A.; Woo, J.J.; Cheigh, H.S.; Chung, H.Y.; Choi, J.S. A new kaempferol 7-O-triglucoside from the leaves of Brassica juncea L. Arch. Pharm. Res. 2002, 25, 621-624. [CrossRef]

30. Shao, Y.; Jiang, J.; Ran, L.; Lu, C.; Wei, C.; Wang, Y. Analysis of Flavonoids and Hydroxycinnamic Acid Derivatives in Rapeseeds (Brassica napus L. var. napus) by HPLC-PDA-ESI(-)-MSn/HRMS. J. Agric. Food Chem. 2014, 62, 2935-2945. [CrossRef]

31. Gerhardt, K.E.; Lampi, M.A.; Greenberg, B.M. The effects of far-red light on plant growth and flavonoid accumulation in Brassica napus in the presence of ultraviolet-B radiation. Photochem. Photobiol. 2008, 84, 1445-1454. [CrossRef]

32. Farag, M.A.; Sharaf Eldin, M.G.; Kassem, H.; Abou el Fetouh, M. Metabolome classification of Brassica napus L. organs via UPLC-QTOF-PDA-MS and their anti-oxidant potential. Phytochem. Anal. 2013, 24, 277-287. [CrossRef]

33. Heinze, M.; Hanschen, F.S.; Wiesner-Reinhold, M.; Baldermann, S.; Grafe, J.; Schreiner, M.; Neugart, S. Effects of developmental stages and reduced UVB and low UV conditions on plant secondary metabolite profiles in pak choi (Brassica rapa subsp. chinensis). J. Agric. Food Chem. 2018, 66, 1678-1692. [CrossRef]

34. Agati, G.; Biricolti, S.; Guidi, L.; Ferrini, F.; Fini, A.; Tattini, M. The biosynthesis of flavonoids is enhanced similarly by UV radiation and root zone salinity in Ligustrum vulgare leaves. J. Plant Physiol. 2011, 168, 204-212. [CrossRef]

35. Neugart, S.; Zietz, M.; Schreiner, M.; Rohn, S.; Kroh, L.W.; Krumbein, A. Structurally different flavonol glycosides and hydroxycinnamic acid derivatives respond differently to moderate UV-B radiation exposure. Physiol. Plant. 2012, 145, 582-593. [CrossRef]

36. Fiol, M.; Adermann, S.; Neugart, S.; Rohn, S.; Mügge, C.; Schreiner, M.; Krumbein, A.; Kroh, L.W. Highly glycosylated and acylated flavonols isolated from kale (Brassica oleracea var. sabellica)—Structure-antioxidant activity relationship. Food Res. Int. 2012, 47, 80-89. [CrossRef]

37. Lang-Mladek, C.; Xie, L.S.; Nigam, N.; Chumak, N.; Binkert, M.; Neubert, S.; Hauser, M.T. UV-B signaling pathways and fluence rate dependent transcriptional regulation of ARIADNE12. Physiol. Plant. 2012, 145, 527-539. [CrossRef]

38. Goetz, M.; Albert, A.; Stich, S.; Heller, W.; Scherb, H.; Krins, A.; Langebartels, C.; Seidlitz, H.K.; Ernst, D. PAR modulation of the UV-dependent levels of flavonoid metabolites in Arabidopsis thaliana (L.) Heynh. leaf rosettes: Cumulative effects after a whole vegetative growth period. Protoplasma 2010, 243, 95-103. [CrossRef]

39. Klem, K.; Ac, A.; Holub, P.; Kovác, D.; Spunda, V.; Robson, T.M.; Urban, O. Interactive effects of PAR and UV radiation on the physiology, morphology and leaf optical properties of two barley varieties. Environ. Exp. Bot. 2012, 75, 52-64. [CrossRef]

40. Price, K.R.; Casuscelli, F.; Colquhoun, I.J.; Rhodes, M.J.C. Hydroxycinnamic acid esters from broccoli florets. Phytochemistry 1997, 45, 1683-1687. [CrossRef]

41. Sullivan, J.H.; Gitz, D.C., 3rd; Liu-Gitz, L.; Xu, C.; Gao, W.; Slusser, J. Coupling short-term changes in ambient UV-B levels with induction of UV-screening compounds. Photochem. Photobiol. 2007, 83, 863-870. [CrossRef]

42. Barnes, P.W.; Flint, S.D.; Slusser, J.R.; Gao, W.; Ryel, R.J. Diurnal changes in epidermal UV transmittance of plants in naturally high UV environments. Physiol. Plant. 2008, 133, 363-372. [CrossRef]

43. Morales, L.O.; Tegelberg, R.; Brosche, M.; Lindfors, A.; Siipola, S.; Aphalo, P.J. Temporal variation in epidermal flavonoids due to altered solar UV radiation is moderated by the leaf position in Betula pendula. Physiol. Plant. 2011, 143, 261-270. [CrossRef]

44. Morales, L.O.; Brosche, M.; Vainonen, J.; Jenkins, G.I.; Wargent, J.J.; Sipari, N.; Strid, A.; Lindfors, A.V.; Tegelberg, R.; Aphalo, P.J. Multiple roles for UV RESISTANCE LOCUS8 in regulating gene expression and metabolite accumulation in Arabidopsis under solar ultraviolet radiation. Plant Physiol. 2013, 161, 744-759. [CrossRef]

45. Bidel, L.P.; Chomicki, G.; Bonini, F.; Mondolot, L.; Soule, J.; Coumans, M.; La Fisca, P.; Baissac, Y.; Petit, V.; Loiseau, A.; et al. Dynamics of flavonol accumulation in leaf tissues under different UV-B regimes in Centella asiatica (Apiaceae). Planta 2015, 242, 545-559. [CrossRef]

46. Del-Castillo-Alonso, M.Á.; Castagna, A.; Csepregi, K.; Hideg, É.; Jakab, G.; Jansen, M.A.K.; Jug, T.; Llorens, L.; Mátai, A.; Martínez-Lüscher, J.; et al. Environmental Factors Correlated with the Metabolite Profile of Vitis vinifera cv. Pinot Noir Berry Skins along a European Latitudinal Gradient. J. Agric. Food Chem. 2016, 64, 8722-8734. [CrossRef]

47. Hectors, K.; van Oevelen, S.; Geuns, J.; Guisez, Y.; Jansen, M.A.K.; Prinsen, E. Dynamic changes in plant secondary metabolites during UV acclimation in Arabidopsis thaliana. Physiol. Plant. 2014, 152, 219-230. [CrossRef]

48. Moreira-Rodríguez, M.; Nair, V.; Benavides, J.; Cisneros-Zevallos, L.; Jacobo-Velázquez, D.A. UVA, UVB light doses and harvesting time differentially tailor glucosinolate and phenolic profiles in broccoli sprouts. Molecules 2017, 22, 1065. [CrossRef]

49. Alboresi, A.; Dall'Osto, L.; Aprile, A.; Carillo, P.; Roncaglia, E.; Cattivelli, L.; Bassi, R. Reactive oxygen species and transcript analysis upon excess light treatment in wild-type Arabidopsis thaliana vs a photosensitive mutant lacking zeaxanthin and lutein. BMC Plant Biol. 2011, 11, 62. [CrossRef]

50. Ali, M.B.; McNear, D.H. Induced transcriptional profiling of phenylpropanoid pathway genes increased flavonoid and lignin content in Arabidopsisleaves in response to microbial products. BMC Plant Biol. 2014, 14, 84. [CrossRef]

51. Graham, T.L. Flavonoid and flavonol glycoside metabolism in Arabidopsis. Plant Physiol. Biochem. 1998, 36, 135-144. [CrossRef]

52. Feng, Y.; Cao, C.-M.; Vikram, M.; Park, S.; Kim, H.J.; Hong, J.C.; Cisneros-Zevallos, L.; Koiwa, H. A Three-Component Gene Expression System and Its Application for Inducible Flavonoid Overproduction in Transgenic Arabidopsis thaliana. PLoS ONE 2011, 6, e17603. [CrossRef] 
53. Harvaux, M.; Kloppstech, K. The protective functions of carotenoid and flavonoid pigments against excess visible radiation at chilling temperature investigated in Arabidopsis npq and tt mutants. Planta 2001, 213, 953-966. [CrossRef]

54. Ruijter, J.M.; Ramakers, C.; Hoogaars, W.M.H.; Karlen, Y.; Bakker, O.; van den Hoff, M.J.B.; Moorman, A.F.M. Amplification efficiency: Linking baseline and bias in the analysis of quantitative PCR data. Nucleic Acids Res. 2009, 37. [CrossRef]

55. Livak, K.J.; Schmittgen, T.D. Analysis of relative gene expression data using real-time quantitative PCR and the 2(T)(-Delta Delta C) method. Methods 2001, 25, 402-408. [CrossRef] 